Research Article

\title{
Handwashing Knowledge, Attitudes, and Practices among Students in Eastern Province Schools, Saudi Arabia
}

\author{
Munthir M. Almoslem $\mathbb{D}^{1},{ }^{1}$ Talal A. Alshehri, ${ }^{1}$ Arwa A. Althumairi $\mathbb{D}^{2}{ }^{2}$ \\ Mohammed T. Aljassim $\mathbb{D}^{1},{ }^{1}$ Mohamed E. Hassan $\mathbb{D}^{3},{ }^{3}$ and Mahmoud M. Berekaa $\mathbb{D}^{1}$ \\ ${ }^{1}$ Environmental Health Dept., College of Public Health, Imam Abdulrahman Bin Faisal University, P.O. Box 1982, \\ Dammam 31441, Saudi Arabia \\ ${ }^{2}$ Health Information Management and Technology Dept., College of Public Health, Imam Abdulrahman Bin Faisal University, \\ P.O. Box 1982, Dammam 31441, Saudi Arabia \\ ${ }^{3}$ Public Health Dept., College of Public Health, Imam Abdulrahman Bin Faisal University, P.O. Box 1982, Dammam 31441, \\ Saudi Arabia
}

Correspondence should be addressed to Mahmoud M. Berekaa; mberekaa@iau.edu.sa

Received 29 December 2020; Revised 23 April 2021; Accepted 8 September 2021; Published 22 September 2021

Academic Editor: Angel Dzhambov

Copyright (C) 2021 Munthir M. Almoslem et al. This is an open access article distributed under the Creative Commons Attribution License, which permits unrestricted use, distribution, and reproduction in any medium, provided the original work is properly cited.

\begin{abstract}
Background. Lack of knowledge about appropriate handwashing practices has caused great concerns for human health, especially in the risk of many communicable diseases. The objective of the current study is to determine the level of handwashing knowledge, attitudes, and practices among school students in Eastern Province Schools, Saudi Arabia. A cross-sectional survey was recruited from November 2019 to March 2020 to assess the level of the students' handwashing knowledge. A reliable questionnaire was prepared (Cronbach's alpha $=0.608$ ) and conducted using a two-stage sampling technique. A total of 271 students participated in the study from primary, middle, and high schools; $80 \%$ were boys, most of whom displayed an acceptable level of knowledge on hand hygiene. Nearly $75 \%$ and $74 \%$ of boys and girls, respectively, gained knowledge about hand hygiene practices from their parents. Only $46 \%$ of the students thought that handwashing is a potential protective measure against diseases, whereas $34 \%$ thought it only removes dirt. Prevalence of handwashing with soap after using the toilet was recognized among 52\% of the students. Additionally, $93 \%$ of the students used water and soap to wash their hands ( $p$ value $<0.001$ ) and $97 \%$ suggested that soap and water are the best methods to wash their hands ( $p$ value $<0.001)$. There was a positive correlation between the mother's education and hand hygiene practices $(p$ value $=0.044)$. Results collectively indicated that handwashing knowledge and practices among school students in the Eastern Province are acceptable interventions in preventing the transmission of infectious diseases such as COVID-19. Indeed, further improvement conducted through specific health education programs to emphasize the role of handwashing in health hygiene is highly recommended.
\end{abstract}

\section{Introduction}

Practicing appropriate handwashing with optimum frequency is a fundamental skill for leading a healthy life $[1,2]$. Handwashing, especially before eating, is believed to be one of the first techniques to protect children, teens, and adults from many communicable diseases $[1,3]$. Generally, there is a progressive increase in risks associated with a wide range of diseases directly correlated with handwashing, for example, water- and foodborne diseases, contagious diseases, severe acute respiratory syndrome (SARS), H1N1 influenza A, norovirus, cholera, malaria, dysentery, meningitis, shigellosis, and multiresistant Staphylococcus aureus [4]. In fact, childhood diarrhoea was found to be significantly correlated with handwashing without soap [5]. Generally, contaminated hands can be a source of infectious diseases, and this happens after picking one's nose or coughing, using the bathroom, and dealing with garbage [6]. Furthermore, handwashing is an essential cause for healthy growth and development in the community $[2,7,8]$. Unfortunately, 
handwashing after visiting the restroom is ill-practiced in many societies, notwithstanding its significant effect on human health [9]. Likewise, nonroutine handwashing is recorded as a major risk factor associated with head, foot, and mouth diseases (HFMD) among children in China and other Asian countries [10]. Generally, hospital-acquired infections can be decreased by the very simple but crucial intervention of handwashing [11]. Similarly, handwashing is considered an efficient preventive measure for children, with a subsequent reduction in child antibiotic use [12].

On the other hand, schools are one of the most important places for promoting health education and programs $[3,13,14]$. The students can gain knowledge, skills, and positive behaviours in terms of handwashing and many other hygiene practices $[3,13]$. According to Al-Bashtawy [3], many students in developing countries have shown a lack of handwashing skills. With handwashing, a simple and largely cost-effective hand hygiene technique, many schools encourage their students to practice handwashing behaviours $[3,13]$.

Besides teachers, parents, and classmates' attitudes significantly influence handwashing and hygiene behaviours and habits among students [15-17]. Nevertheless, students' hygiene knowledge, attitudes, and practices have shown significant discrepancies between genders [18]. It has been found that the interventions of handwashing and personal hygiene in school children have led to a significant reduction in diarrhoea cases and absence rates among students [19]. Moreover, the intervention of handwashing has significantly improved schoolchildren's knowledge and practices, helping them to communicate the latter with their parents efficiently [20].

Several studies have been conducted to investigate the issues regarding handwashing and general hygiene in school students. Handwashing, especially after visiting bathrooms, has a significant effect on the spread of parasitic infections, with increased cases of the latter present among school students in many countries [13, 21, 22].

In Saudi Arabia, several studies have been conducted to explore students' knowledge and attitudes towards hand hygiene practices in many cities including Abha, Majma'ah, and Al-Ahsa [23-29]. On the other hand, no study has been conducted to assess handwashing practices and knowledge among school students in Eastern Province, Saudi Arabia. However, many researchers have studied general hygiene practices and food hygiene at a school level.

To fill the gap of knowledge on handwashing practices among school students in Eastern Province, Saudi Arabia, the current study was conducted for the first time. This study aims to determine the level of the school students' handwashing knowledge and practices in three different cities in Eastern Province (Dammam, Dhahran, and Khobar) and identify the sources of knowledge about hand hygiene. Furthermore, the study attempts to find out the correlation between student characteristics and hand hygiene practices.

\section{Materials and Methods}

2.1. Study Location. The study was conducted in selected schools in the major three cities in the Eastern Province
(Dammam, Dhahran, and Khobar), Saudi Arabia, between November 2019 and March 2020.

2.2. Sampling Design. A cross-sectional survey was recruited from November 2019 to March 2020 to assess the level of the students' handwashing knowledge. Data collection was based on a survey questionnaire adapted from Dajaan et al. (2018). The questionnaire was translated to Arabic, and its contents were validated by public health experts. Cronbach's alpha test was performed using SPSS version 19.0 to check the reliability of the questionnaire and was found to be 0.608 .

Random sampling was performed using a two-stage sampling technique that involved a fixed number of schools for each stratum in three major cities in Eastern Province, namely Dammam, Khobar, and Dhahran. In the first stage, every $35^{\text {th }}$ school was randomly selected from a list of 1,068 schools in the major three cities in the Eastern Province. In the second stage, every $3^{\text {rd }}$ student was randomly selected from a students' list of each school. The number of students spread proportionally across the schools, and 271 students were selected from 30 schools. In addition, a checklist was created to inspect the availability of handwashing facilities at schools. Assistance has been provided to respondents to explain the questions as well as to fill out the questionnaires. The questionnaires were collected on the same day of each visited school after assuring that all questions were answered with care and attention.

The questionnaire included questions on student's parental education and sociodemographic characteristics. In fact, there were 16 questions assessing the perceived levels of knowledge on hand hygiene practices, with a clear response to hand hygiene acquisition and performance. Indeed, the distribution of student responses on their hand hygiene practice was targeted by 11 questions.

2.3. Inclusion and Exclusion Criteria. Primary, intermediate, and secondary school students (male and female) from the selected schools were included in the study. However, students with mental or physical disabilities from the selected schools were excluded.

2.4. Statistical Analysis. The normality of data was tested using a boxplot diagram. A descriptive analysis was the first section presenting the percentage of responses to each domain. The bivariate analysis comprised a Chi-square score analysis for categorical two-group data and ANOVA for categorical data with more than two groups to assess the relationship between student characteristics and the score of hand hygiene practices. All statistical analyses were performed using the SPSS 19.0 program (SPSS Inc., Chicago, IL, USA).

2.5. Ethical Considerations. Ethical permission was obtained from the Institutional Review Board (IRB) of Imam Abdulrahman Bin Faisal University, Dammam, KSA (ethical permission number: IRB-2021-057-CPH). 


\section{Results}

3.1. Students' Characteristics. Among the 271 students who participated in the study, $80 \%$ were boys, and $71 \%$ were above 14 years old, that is, mostly from high school (Table 1). There was great variation in terms of parental education, with half of the mothers holding high school and undergraduate degrees (26\% and $35 \%$, respectively), while twothirds of the fathers had gained undergraduate and postgraduate degrees ( $27 \%$ and $28 \%$, respectively).

Seventy-five percent of boys and $74 \%$ of girls agreed that they had learnt about hand hygiene practices from their parents (Table 2 and Figure 1). For all age groups, parents had the greatest impact as a means of transmitting handwashing education (Table 2).

As graphically presented in Figure 1, approximately $74-75 \%$ of students of all ages gained their knowledge of hand hygiene practices from their parents.

3.2. Perceived Knowledge of Hand Hygiene. Assessing the students' perceived knowledge on hand hygiene indicated that a majority of participants had a high level of knowledge on hand hygiene (Table 3). Moreover, most students (87\%; $p$ value $=0.001)$ recognized that washing hands with water and soap at schools is significant. Interestingly, $91.1 \%$ ( $p$ value $=0.001)$ of students had been educated on how to wash their hands. Unfortunately, only $46 \%$ thought that handwashing prevents diseases, and approximately $40 \%$ thought it removes dirt, whereas $69 \%$ did not believe that handwashing could remove germs. Additionally, $82.7 \%$ of students recognized the significant impact of handwashing on personal hygiene ( $p$ value $=0.001)$. Regarding the use of soap in handwashing, $77.5 \%$ of students washed their hands before and after eating, whereas $52 \%$ washed their hands after using the toilet and $83 \%$ while preparing food $(p$ value $=0.001$ ).

Regarding students' performance, $92 \%$ used water and soap to wash their hands (Figure 2), and 97\% ( $p$ value $<0.001$ ) agreed that using soap and water is the best method to wash their hands (Table 4). Surprisingly, 62\% learnt to wash their hands at home and $18 \%$ at school (Figure 3).

The students were asked about their perceived hand hygiene practices (Table 5), with the majority of their answers showing evidence of positive practices and with more than $80 \%$ agreeing on the best forms of hand hygiene practice $(p$ value $<0.001)$. However, when they were faced with confirming the statement "I always wash my hands after playing with friends," only $61 \%$ did so.

A bivariate analysis to assess the relation between student characteristics and scores of hand hygiene practice (score of 12) was conducted. The analysis indicated that the student's gender and their father's level of education have no significant impact on perceived practices; however, age had a significant impact on their perceived practice ( $p$ value $<0.015$ ), and the older the student, the more aware of hand hygiene practices they were. Additionally, the students' mothers' levels of education had a significant relationship to hand hygiene practices ( $p$ value $=0.044)$, as students with a mother who had an elementary or high school education $(p$ value $=0.071$ and 0.014 , respectively) displayed the highest scores of perceived practices of hand hygiene (Tables 6 and 7).

\section{Discussion}

The current study was conducted to assess the level of handwashing knowledge and practice among students in the Eastern Province, Saudi Arabia. Consideration was given to the relationship between students' backgrounds and hand hygiene practices. Results revealed that most of the students $(80 \%)$ possessed an awareness of hand hygiene. Similar findings were recorded among male primary school students in the city of Abha, Saudi Arabia [30]. In concordance, a study in Abha revealed that $86.6 \%$ of the students have acknowledged that respiratory tract infections can be reduced if the proper handwashing practices are maintained [26]. Moreover, Hazazi et al. [30] found that approximately $95 \%$ of the students realized the importance of hand hygiene, especially in disease spreading through person-to-person contact. Also, in a study to detect the level of knowledge and practice as a preventive measure to combat COVID-19 disease in Saudi Arabia, Siddiqui et al. [31] revealed that $84 \%$ of the population realizes and practices handwashing. On the contrary, Dajaan [15] revealed that only $37.67 \%$ of primary school students in Ghana realized the importance of handwashing in disease prevention. Compared to the studies carried out in other Saudi Arabia cities, Ghana, and India, school students in Eastern Province recorded a better awareness towards hand-hygiene-related knowledge and practices $[8,15,32]$.

Approximately $75 \%$ of the students had learnt hand hygiene practices from their parents; these findings were expected, as the students in the study location generally come from a high socioeconomic status. On the contrary, Al-Hazmi et al. [25] revealed that knowledge of preventive measures against infectious diseases is higher among college students than in schools, and the media is the major source of information on those measures, rather than academic institutions' programs. Moreover, a study in Al-Ahsa region, Saudi Arabia, explicits that sociodemographic factors and personal hygiene habits are associated with the prevalence of infectious diseases [29]. Most of the students (97\%) agreed that soap and water is the best method for washing their hands; this result was consistent with some other previous studies [13, 30, 33-35].

Only $46 \%$ of the students thought that handwashing prevents diseases, and $34 \%$ of them thought that it removes dirt. Concurrently, Dajaan et al. [15] have found that $100 \%$ of Saudi school students recognize the importance of soap and water in handwashing, with their results also showing that $37.67 \%$ of the respondents in the study washed their hands to prevent disease, and $21.33 \%$ washed their hands to remove germs and dirt [15].

Moreover, $86 \%$ and $87 \%$ of the students washed their hands before eating and after using the toilet, respectively. In Majma'ah, a study compared food hygiene practices, 
TABLE 1: Distribution of student characteristics.

\begin{tabular}{|c|c|c|c|c|}
\hline Student characteristics & $\begin{array}{c}N \\
271 \\
\end{array}$ & Percentage & $\mathrm{Chi}^{2}(\mathrm{df})$ & $p$ value \\
\hline \multicolumn{5}{|l|}{ Gender } \\
\hline Boy & 218 & 80 & $100.5(1)$ & $<0.001$ \\
\hline Girl & 53 & 20 & & \\
\hline \multicolumn{5}{|l|}{ Age } \\
\hline 9-11 years & 59 & 22 & $180.1(2)$ & $<0.001$ \\
\hline $12-14$ years & 20 & 7 & & \\
\hline Above 14 years & 192 & 71 & & \\
\hline \multicolumn{5}{|l|}{ Class level } \\
\hline Elementary school & 59 & 22 & $180.1(2)$ & $<0.001$ \\
\hline Secondary school & 20 & 7 & & \\
\hline High school & 192 & 71 & & \\
\hline Maternal education level & & & $133.1(5)$ & $<0.001$ \\
\hline No formal education & 21 & 8 & & \\
\hline Elementary and secondary level & 23 & 9 & & \\
\hline High school level & 69 & 26 & & \\
\hline Undergraduate level (diploma or bachelor's) & 95 & 35 & & \\
\hline Postgraduate level (master's, doctoral, or above) & 37 & 14 & & \\
\hline I do not know & 26 & 1 & & \\
\hline Paternal education level & & & $121.9(5)$ & $<0.001$ \\
\hline No formal education & 15 & 6 & & \\
\hline Elementary and secondary level & 14 & 5 & & \\
\hline High school level & 61 & 23 & & \\
\hline Undergraduate level (diploma or bachelor's) & 74 & 27 & & \\
\hline Postgraduate level (master, doctoral, or above) & 76 & 28 & & \\
\hline I do not know & 31 & 1 & & \\
\hline
\end{tabular}

TABLE 2: The relationship between gender, age distributions, and the teaching means.

\begin{tabular}{|c|c|c|c|c|c|c|c|c|c|c|}
\hline \multirow[t]{2}{*}{ Student characteristics } & \multicolumn{2}{|c|}{ Teacher } & \multicolumn{2}{|c|}{$\begin{array}{l}\text { Health } \\
\text { officer }\end{array}$} & \multicolumn{2}{|c|}{ Parent } & \multicolumn{2}{|c|}{ Missing } & \multirow[t]{2}{*}{$\mathrm{Chi}^{2}(\mathrm{df})$} & \multirow[t]{2}{*}{$p$ value } \\
\hline & $n$ & $\%$ & $n$ & $\%$ & $n$ & $\%$ & $n$ & $\%$ & & \\
\hline \multicolumn{11}{|l|}{ Gender } \\
\hline Boys & 18 & 9 & 34 & 17 & 152 & 75 & 14 & 6 & $0.671(2)$ & 0.715 \\
\hline Girls & 3 & 6 & 10 & 20 & 36 & 74 & 4 & 8 & & \\
\hline Total & 21 & 8 & 44 & 17 & 188 & 74 & 18 & 7 & & \\
\hline \multicolumn{11}{|l|}{ Age } \\
\hline $9-11$ years & 10 & 17 & 8 & 63 & 37 & 7 & 4 & 7 & $12.171(4)$ & 0.016 \\
\hline $12-14$ years & 2 & 10 & 6 & 30 & 12 & 60 & 0 & 0 & & \\
\hline Above 14 years & 9 & 5 & 30 & 16 & 139 & 72 & 14 & 7 & & \\
\hline Total & 21 & 8 & 44 & 16 & 188 & 69 & 18 & 7 & & \\
\hline
\end{tabular}

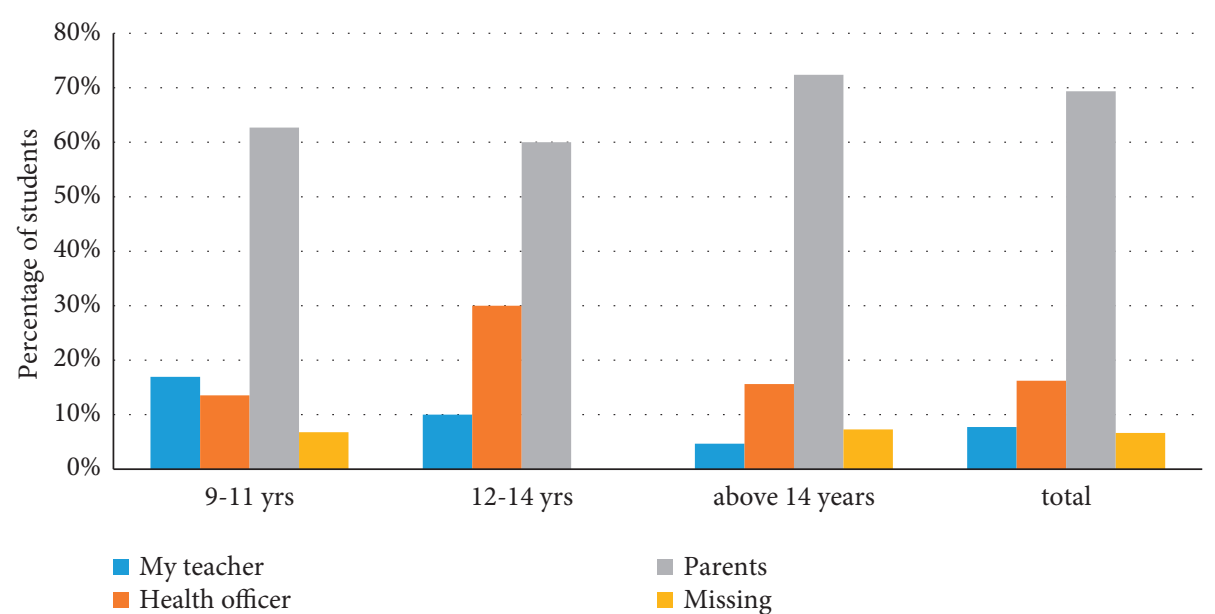

FIGURE 1: Major sources of knowledge about hand hygiene among school students between 9 and 14 years old. 
TABle 3: Students' responses to perceived levels of knowledge on hand hygiene practices.

\begin{tabular}{|c|c|c|c|c|c|}
\hline \multirow{2}{*}{ Students' perceived knowledge } & \multicolumn{2}{|c|}{ Yes } & \multicolumn{2}{|c|}{ No } & \multirow{2}{*}{$p$ value } \\
\hline & $N$ & $\%$ & $N$ & $\%$ & \\
\hline 1.01. Is it important to wash your hands with soap when in school? & 236 & 87.1 & 33 & 12.2 & $<0.001$ \\
\hline 1.02. Is it important to wash your hands with water to prevent diseases? & 121 & 44.6 & 141 & 52.0 & 0.217 \\
\hline 1.03. Is it important to wash your hands with soap to prevent diseases? & 124 & 45.8 & 138 & 50.9 & 0.217 \\
\hline 1.04. Is it important to wash your hands to remove germs? & 74 & 27.3 & 187 & 69.0 & 0.387 \\
\hline 1.05. Is it important to wash your hands to remove dirt? & 108 & 39.9 & 153 & 56.5 & $<0.001$ \\
\hline 1.06. Is it important to wash your hands for personal hygiene? & 224 & 82.7 & 37 & 13.7 & $<0.001$ \\
\hline 1.07. Have you ever been educated on how to wash your hands? & 247 & 91.1 & 23 & 8.5 & $<0.001$ \\
\hline 1.08. Do you wash your hands before and after eating? & 210 & 77.5 & 60 & 22.1 & $<0.001$ \\
\hline 1.09. Do you wash your hands after handling rubbish/garbage? & 174 & 64.2 & 96 & 35.4 & $<0.001$ \\
\hline 1.10. Do you wash your hands before preparing food? & 226 & 83.4 & 43 & 15.9 & $<0.001$ \\
\hline 1.11. Do you wash your hands after using the toilet? & 141 & 52.0 & 128 & 47.2 & $<0.001$ \\
\hline 1.12. Do you wash your hands after playing with friends? & 185 & 68.3 & 85 & 31.4 & 0.428 \\
\hline 1.13. Do you wash your hands after coughing or blowing your nose? & 185 & 68.3 & 85 & 31.4 & $<0.001$ \\
\hline 1.14. Did you wash your hands in school? & 230 & 84.9 & 40 & 14.8 & $<0.001$ \\
\hline 1.15. Did you wash your hands in school with soap? & 143 & 52.8 & 127 & 46.9 & 0.330 \\
\hline 1.16. Is it necessary to dry your hands after washing? & 207 & 76.4 & 63 & 23.2 & $<0.001$ \\
\hline
\end{tabular}

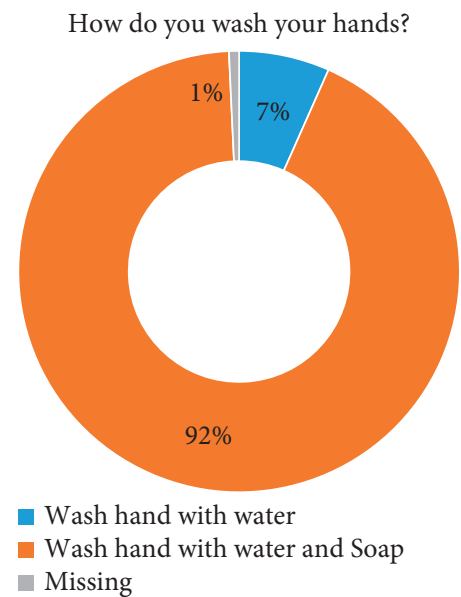

FIGURE 2: Student responses on their hand hygiene methods.

including handwashing, between primary, intermediate, and secondary school students and found that the students demonstrated good levels of practice, even though attitudes and levels of knowledge were considerably reasonable [28]. Hazazi et al. [30] revealed that more than $90 \%$ of primary year school students use soap in handwashing especially before and after eating and also after using the toilet. Unfortunately, only $39.88 \%$ of primary school students in Ghana use soap in handwashing after visiting the toilet [15]. Remarkably, UNICEF [36] declares that the two most vital moments of handwashing happen before eating and after using the toilet, supporting the findings of the current study.

Also, the results remarkably revealed that approximately $86 \%$ and $87 \%$ of the students washed their hands before eating and after using the toilet. The role of handwashing as an efficient preventative technique against many infectious diseases, for example, impetigo, diarrhoea, HFMD, and the novel COVID-19 has been reported by many scientists $[4,10,35,37,38]$. Recently, the role of hand hygiene behaviour in COVID-19 prevention among primary school students has been studied in China [39]. Approximately, $42.05 \%$ of the students showed good behaviour and were significantly affected by many factors including mother's educational background. In a study to detect the level of knowledge and practices during the COVID-19 pandemic among the Saudi population, it was found that most of the participants preferred handwashing to alcohol disinfection [40].

Indeed, the use of soap in handwashing by approximately $86.5 \%$ of the students is greater in comparison with other countries (42\% to $49 \%$ ) [4]. Also, handwashing with soap plays a crucial role in the prevention of water- and foodborne diseases by $50 \%$ to $70 \%$, and pneumonia, impetigo, and diarrhoeal diseases by $40 \%$ to $50 \%$ [4]. Also, in Riyadh, a study revealed that handwashing with soap is 
TABLE 4: Student responses on their hand hygiene performance.

\begin{tabular}{|c|c|c|c|}
\hline Student performance & $N$ & Percent & $p$ value \\
\hline \multicolumn{3}{|l|}{ How do you wash your hands? } & $<0.001$ \\
\hline Wash hands with water & 18 & 7 & \\
\hline Wash hands with water and soap & 251 & 93 & \\
\hline Missing & 2 & 1 & \\
\hline Total & 271 & 100 & \\
\hline \multicolumn{3}{|c|}{ Where have you ever been educated on how to wash your hands? } & $<0.001$ \\
\hline School & 50 & 18 & \\
\hline Home & 167 & 62 & \\
\hline Media & 20 & 7 & \\
\hline Community & 20 & 7 & \\
\hline Missing & 14 & 5 & \\
\hline Total & 271 & 100 & \\
\hline \multicolumn{3}{|c|}{ What is the best to use when washing your hands? } & $<0.001$ \\
\hline Water only & 7 & 3 & \\
\hline Water and soap & 263 & 97 & \\
\hline Missing & 1 & 0 & \\
\hline Total & 271 & 100 & \\
\hline \multicolumn{3}{|c|}{ Which soap type is best to use in handwashing? } & $<0.001$ \\
\hline Liquid soap & 185 & 68 & \\
\hline Bar soap & 46 & 17 & \\
\hline Powder detergent & 5 & 2 & \\
\hline Do not know & 32 & 12 & \\
\hline Missing & 3 & 1 & \\
\hline Total & 271 & 100 & \\
\hline
\end{tabular}

Where Have you ever been educated on how to wash your hands?
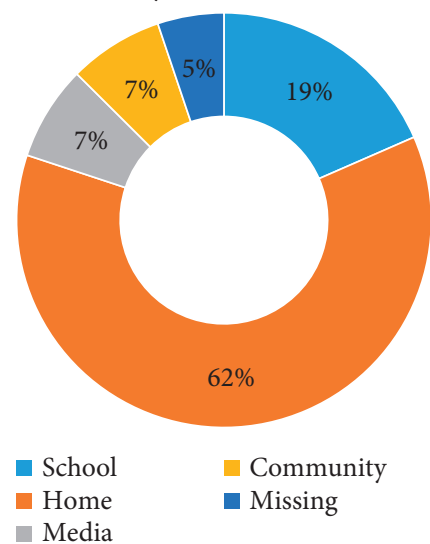

Figure 3: Student responses on the place of hand hygiene knowledge acquisition.

negatively correlated with students' absence in school [27]. Interestingly, the prevalent use of soap with handwashing is recorded as an efficient measure for reducing contamination of the hands due to the potentially lethal effects of microbial contaminants [41, 42].

Finally, in concordance with previous studies, maternal education levels and student age are significantly correlated with good hand hygiene practices among school students.
However, the gender of school students was not correlated with the level of handwashing. On the contrary, Alshammary et al. [43] revealed that Saudi females are equipped with a higher level of knowledge and practice on hand hygiene than males during the COVID-19 pandemic $(86 \%$ and $80 \%$, respectively). Moreover, Dajaan et al. [15] identified that female students have higher handwashing practices than males. 
TABLe 5: Distribution of student responses on their hand hygiene practice.

\begin{tabular}{|c|c|c|c|c|c|}
\hline \multirow{2}{*}{ Students' perceived practice } & \multicolumn{2}{|c|}{ Yes } & \multicolumn{2}{|c|}{ No } & \multirow{2}{*}{$p$ value } \\
\hline & $N$ & $\%$ & $N$ & $\%$ & \\
\hline 2.01. I always wash my hands before and after eating & 238 & 88 & 28 & 10 & $<0.001$ \\
\hline 2.02. I always wash my hands with soap before and after eating & 235 & 87 & 35 & 13 & $<0.001$ \\
\hline 2.03. I always wash my hands after visiting the toilet & 232 & 86 & 31 & 11 & $<0.001$ \\
\hline 2.04. I always wash my hands with soap after handling garbage & 239 & 88 & 31 & 11 & $<0.001$ \\
\hline 2.05. I always wash my hands after playing with friends & 165 & 61 & 100 & 37 & $<0.001$ \\
\hline 2.06. I always wash my hands with soap after playing with friends & 171 & 63 & 97 & 36 & $<0.001$ \\
\hline 2.07. I always wash my hands after blowing my nose or coughing & 219 & 81 & 46 & 17 & $<0.001$ \\
\hline 2.08. I always wash my hands with water after blowing my nose or coughing & 223 & 82 & 45 & 17 & $<0.001$ \\
\hline 2.09. I always wash my hands with soap after blowing my nose or coughing & 223 & 82 & 45 & 17 & $<0.001$ \\
\hline 2.10. I always wash my hands when they are visibly dirty & 235 & 87 & 28 & 10 & $<0.001$ \\
\hline 2.11. I always wash my hands with soap when they are visibly dirty & 261 & 96 & 9 & 3 & $<0.001$ \\
\hline
\end{tabular}

TABLE 6: Bivariate analysis of students' means scores of hygiene practices according to their background.

\begin{tabular}{|c|c|c|c|c|c|c|}
\hline Student background & $N^{*}$ & Mean & SD & Std. error mean & $T$-test ${ }^{\$}$ & $p$ value \\
\hline \multicolumn{7}{|l|}{ Gender } \\
\hline Boy & 218 & 10.05 & 2.333 & 0.158 & 1.510 & 0.132 \\
\hline Girl & 53 & 9.51 & 2.259 & & & \\
\hline \multicolumn{7}{|l|}{ Age } \\
\hline $9-11$ years & 59 & 10.59 & 2.102 & 0.310 & 4.247 & 0.015 \\
\hline $12-14$ years & 20 & 9.00 & 2.362 & & & \\
\hline Above 14 years & 192 & 9.84 & 2.347 & & & \\
\hline \multicolumn{7}{|l|}{ Class level } \\
\hline Elementary school & 59 & 10.59 & 2.102 & 4.247 & 2 & 0.015 \\
\hline Secondary school & 20 & 9.00 & 2.362 & & & \\
\hline High school & 192 & 9.84 & 2.347 & & & \\
\hline \multicolumn{7}{|l|}{ Maternal education level } \\
\hline No formal education & 21 & 9.71 & 2.148 & 2.325 & 5 & 0.044 \\
\hline Elementary and secondary level & 23 & 10.39 & 2.061 & & & \\
\hline High school level & 69 & 10.35 & 1.984 & & & \\
\hline Undergraduate level & 95 & 9.85 & 2.445 & & & \\
\hline Postgraduate level & 37 & 8.89 & 2.706 & & & \\
\hline I do not know & 7 & 10.57 & 1.512 & & & \\
\hline \multicolumn{7}{|l|}{ Paternal education level } \\
\hline No formal education & 15 & 10.87 & 1.407 & 1.214 & 5 & 0.303 \\
\hline Elementary and secondary level & 14 & 10.14 & 2.070 & & & \\
\hline High school level & 61 & 9.92 & 2.193 & & & \\
\hline Undergraduate level & 74 & 9.66 & 2.495 & & & \\
\hline Postgraduate level & 76 & 9.76 & 2.487 & & & \\
\hline I do not know & 10 & 11.00 & 1.414 & & & \\
\hline
\end{tabular}

* The total number of complete cases is $271 .{ }^{\$} \mathrm{~F}$-score for more than two groups. 
TABLE 7: Multivariate linear regression of student characteristics and means scores of hygiene practices.

\begin{tabular}{|c|c|c|c|c|c|c|}
\hline \multirow{2}{*}{$\begin{array}{l}\text { Student characteristics } \\
\text { Gender }\end{array}$} & \multirow[t]{2}{*}{$N^{*}$} & \multirow[t]{2}{*}{ Beta } & \multirow[t]{2}{*}{$t$-value } & \multirow[t]{2}{*}{$p$ value } & \multicolumn{2}{|c|}{$95 \% \mathrm{CI}$} \\
\hline & & & & & & \\
\hline Boy & 218 & 1.00 (ref) & & & & \\
\hline Girl & 53 & -0.022 & -0.305 & 0.761 & -0.970 & 0.710 \\
\hline \multicolumn{7}{|l|}{ Age } \\
\hline $9-11$ years & 59 & 1.00 (ref) & & & & \\
\hline $12-14$ years & 20 & -0.174 & -2.141 & $0.033^{*}$ & -2.963 & -0.124 \\
\hline Above 14 years & 192 & -0.146 & -2.125 & $0.035^{*}$ & -1.436 & -0.055 \\
\hline \multicolumn{7}{|l|}{ Class level } \\
\hline Elementary school & 59 & 1.00 (ref) & & & & \\
\hline Secondary school & 20 & -0.140 & -1.635 & 0.103 & -2.739 & 0.254 \\
\hline High school & 192 & -0.128 & -1.535 & 0.126 & -1.487 & 0.184 \\
\hline \multicolumn{7}{|l|}{ Mother education } \\
\hline No formal education & 21 & 1.00 (ref) & & & & \\
\hline Elementary and secondary level & 23 & 0.158 & 1.811 & 0.071 & -0.115 & 2.753 \\
\hline High school level & 69 & 0.312 & 2.468 & $0.014^{*}$ & 0.336 & 2.989 \\
\hline Undergraduate level & 95 & 0.223 & 1.691 & 0.092 & -0.178 & 2.344 \\
\hline Postgraduate level & 37 & 0.012 & 0.110 & 0.913 & -1.321 & 1.477 \\
\hline I do not know & 7 & 0.039 & 0.331 & 0.741 & -2.835 & 3.979 \\
\hline \multicolumn{7}{|l|}{ Father education } \\
\hline No formal education & 15 & 1.00 (ref) & & & & \\
\hline Elementary and secondary level & 14 & -0.101 & -1.210 & 0.228 & -2.790 & 0.667 \\
\hline High school level & 61 & -0.242 & -1.885 & 0.061 & -2.751 & 0.060 \\
\hline Undergraduate level & 74 & -0.253 & -1.866 & 0.063 & -2.707 & 0.073 \\
\hline Postgraduate level & 76 & -0.166 & -1.210 & 0.228 & -2.250 & 0.538 \\
\hline I do not know & 10 & 0.011 & 0.093 & 0.926 & -2.758 & 3.033 \\
\hline
\end{tabular}

${ }^{*}$ The total number of complete cases is 271 .

\section{Conclusions}

The purpose of the current study was to determine the level of school students' handwashing knowledge and practices, with a special emphasis on their source of knowledge about hand hygiene. Additionally, the correlation between students' backgrounds and hand hygiene practices was clearly discussed. Interestingly, more than $80 \%$ of the students have high levels of hand hygiene awareness, especially learnt at home. Unlike the students' fathers' education levels, their mothers' education levels, and the age of the students have been found to have a significant impact on hand hygiene practices and behaviour. The work presented in this study can serve as a basis for the construction of awareness programs to promote hand hygiene education and practices against infectious diseases, for example, COVID-19 and similar pandemics. Further studies are needed to understand how hand hygiene is practiced at home and in school while relating this practice to infectious disease transmission and risk factors.

\section{Data Availability}

Raw data are available from the corresponding author upon reasonable request.

\section{Conflicts of Interest}

The authors declare that there are no conflicts of interest regarding the publication of this paper.

\section{Acknowledgments}

The researchers would like to thank the Ministry of Health, school students, and teachers for their help and cooperation. Also, the researchers have great gratitude towards the students of the Public Health College at Imam Abdulrahman Bin Faisal for their help in distributing the questionnaires among the students.

\section{References}

[1] V. Curtis and S. Cairncross, "Effect of washing hands with soap on diarrhoea risk in the community: a systematic review," The Lancet Infectious Diseases, vol. 3, no. 5, pp. 275-281, 2003.

[2] M. Steiner-Asiedu, S. E. Van-Ess, M. Papoe, J. Setorglo, D. K. Asiedu, and A. K. Anderson, "Hand-washing practices among school children in Ghana," Current Research Journal of Social Sciences, vol. 3, no. 4, pp. 293-300, 2011.

[3] M. ALBashtawy, "Personal hygiene in school children aged 6-12 years in Jordan," British Journal of School Nursing, vol. 10, no. 8, pp. 395-398, 2015.

[4] M. S. Lee, S. J. Hong, and Y. T. Kim, "Hand-washing with soap and national hand-washing projects in Korea: focus on the national hand-washing survey, 2006-2014," Epidemiology and Health, vol. 37, Article ID e2015039, 2015.

[5] N. E. Soboksa, S. R. Gari, A. B. Hailu, and B. M. Alemu, "Association between microbial water quality, sanitation and hygiene practices and childhood diarrhea in Kersa and Omo Nada districts of Jimma Zone, Ethiopia," PloS One, vol. 15, no. 2, Article ID e0229303, 2020. 
[6] F. Majorin, M. C. Freeman, S. Barnard, P. Routray, S. Boisson, and T. Clasen, "Child feces disposal practices in rural Orissa: a cross sectional study," PloS One, vol. 9, no. 2, Article ID e89551, 2014.

[7] WHO World Health Organization. Handwashing Day. Planners Guide. Clean Hands Save Lives. CDC Report. 2008; 15th October. Retrieved From: https://www.cdc.gov/ handwashing/global-handwashing-day.html.

[8] C. Garbutt, G. Simmons, D. Patrick, and T. Miller, "The public hand hygiene practices of New Zealanders: a national survey," New Zealand Medical Journal, vol. 120, no. 1265, p. U2810, 2007.

[9] M. C. Freeman, M. E. Stocks, O. Cumming et al., "Hygiene and health: systematic review of hand-washing practices worldwide and update of health effects," Tropical Medicine \& International Health, vol. 19, no. 8, pp. 906-916, 2014.

[10] D. Zhang, Z. Li, W. Zhang et al., "Hand-washing: the main strategy for avoiding hand, foot and mouth disease," International Journal of Environmental Research and Public Health, vol. 13, no. 6, p. 610, 2016.

[11] U. Tyagi and K. C. Barwal, "Ignac Semmelweis-father of hand hygiene," Indian Journal of Surgery, vol. 82, no. 3, pp. 276-277, 2020.

[12] E. Dean, "Hand-washing," Nursing Children and Young People, vol. 29, no. 2, p. 11, 2017.

[13] C. Lopez-Quintero, P. Freeman, and Y. Neumark, "Handwashing among school children in Bogota, Colombia," American Journal of Public Health, vol. 99, no. 1, pp. 94-101, 2009.

[14] M. Sarkar, "Personal hygiene among primary school children living in a slum of Kolkata, India," Journal of Preventive Medicine and Hygiene, vol. 54, no. 3, pp. 153-158, 2013.

[15] D. S. Dajaan, H. O. Addo, L. Ojo et al., "Hand-washing knowledge and practices among public primary schools in the Kintampo Municipality of Ghana," International Journal of Community Medicine and Public Health, vol. 5, no. 6, pp. 2205-2216, 2018.

[16] C. Sun, Q. Wang, S. Poudel Adhikari et al., "Correlates of school children's hand washing: a study in Tibetan primary schools," International Journal of Environmental Research and Public Health, vol. 16, no. 17, Article ID 3217, 2019.

[17] J. B. Tidwell, A. Gopalakrishnan, A. Unni et al., "Impact of a teacher-led school hand-washing program on children's hand-washing with soap at school and home in Bihar, India," PloS One, vol. 15, no. 2, Article ID e0229655, 2020.

[18] G. D. Gebreeyessus and D. B. Adem, "Knowledge, attitude, and practice on hygiene and morbidity status among tertiary students: the case of Kotebe Metropolitan University, Addis Ababa, Ethiopia," Journal of Environmental and Public Health, vol. 2018, Article ID 2094621, 9 pages, 2018.

[19] A. Joshi and C. Amadi, "Impact of water, sanitation, and hygiene interventions on improving health outcomes among school children," Journal of Environmental and Public Health, vol. 8456, Article ID 984626, 2013.

[20] A. Garg, D. K. Taneja, S. K. Badhan, and G. K. Ingle, "Impact of a school-based hand-washing promotion program on knowledge and hand-washing behavior of girl students in a middle school of Delhi," Indian Journal of Public Health, vol. 57, no. 2, p. 109, 2013.

[21] T. Hailegebriel, "Undernutrition, intestinal parasitic infection and associated risk factors among selected primary school children in Bahir Dar, Ethiopia," BMC Infectious Diseases, vol. 18, no. 1, p. 394, 2018.
[22] A. S. Hussein, "Prevalence of intestinal parasites among school children in northern districts of West Bank-Palestine," Tropical Medicine \& International Health, vol. 16, no. 2, pp. 240-244, 2011.

[23] M. A. Bakarman, M. Baig, A. A. Malik et al., "Hand hygiene knowledge and attitude of medical students in western Saudi Arabia," PeerJ, vol. 7, Article ID e6823, 2019.

[24] R. Hamadah, R. Kharraz, A. Alshanqity, D. AlFawaz, A. M. Eshaq, and A. Abu-Zaid, "Hand hygiene: knowledge and attitudes of fourth-year clerkship medical students at Alfaisal University, College of Medicine, Riyadh, Saudi Arabia," Cureus, vol. 7, no. 8, Article ID e310, 2015.

[25] A. Al-Hazmi, I. Gosadi, A. Somily, S. Alsubaie, and A. Bin Saeed, "Knowledge, attitudes and practices of secondary schools and university students toward the Middle East Respiratory Syndrome epidemic in Saudi Arabia: a cross-sectional study," Saudi Journal of Biological Sciences, vol. 25, no. 3, pp. 572-577, 2018.

[26] M. Saleh, "Knowledge of male secondary school students regarding prevention of acute respiratory infections in Abha City, KSA," International Journal of Medical Science and Public Health, vol. 2, no. 1, p. 129, 2013.

[27] A. A. Alzaher, S. S. Almudarra, M. H. Mustafa, and I. M. Gosadi, "The importance of hand hygiene education on primary schoolgirls' absence due to upper respiratory infections in Saudi Arabia: a cluster randomized controlled trial," Saudi Medical Journal, vol. 39, no. 10, pp. 1044-1049, 2018.

[28] M. Almansour, W. Sami, O. S. Al-Rashedy, R. S. Alsaab, A. S. Alfayez, and N. R. Almarri, "Knowledge, attitudes, and practices (KAP) of food hygiene among school students in Majmaah city, Saudi Arabia," Journal of the Pakistan Medical Association, vol. 66, no. 4, pp. 442-446, 2016.

[29] H. I. Al-Mohammed, T. T. Amin, E. Aboulmagd, H. R. Hablus, and B. O. Zaza, "Prevalence of intestinal parasitic infections and its relationship with socio-demographics and hygienic habits among male primary schoolchildren in Al-Ahsa, Saudi Arabia," Asian Pacific Journal of Tropical Medicine, vol. 3, no. 11, pp. 906-912, 2010.

[30] A. Hazazi, S. Chandramohan, J. Khan, and M. AL-Mohaithef, "Knowledge, attitude and practices regarding personal hygiene among the male primary school children in Abha, Kingdom of Saudi Arabia: a cross-sectional study," Helix, vol. 8, no. 2, pp. 3215-3223, 2018.

[31] A. A. Siddiqui, F. Alshammary, J. Amin et al., "Knowledge and practice regarding prevention of COVID-19 among the Saudi Arabian population," Work, vol. 66, no. 4, pp. 767-775, 2020.

[32] P. Gawai, S. Taware, A. Chatterjee, and H. Thakur, "A cross sectional descriptive study of hand-washing knowledge and practices among primary school children in Mumbai, Maharashtra, India," International Journal of Community Medicine and Public Health, vol. 3, no. 10, pp. 2958-2966, 2016.

[33] M. Assefa and A. Kumie, "Assessment of factors influencing hygiene behaviour among school children in Mereb-Leke District, Northern Ethiopia: a cross-sectional study," BMC Public Health, vol. 14, no. 1, Article ID 1000, 2014.

[34] C. E. O’ Reilly, M. C. Freeman, M. Ravani et al., "The impact of a school-based safe water and hygiene programme on knowledge and practices of students and their parents: Nyanza Province, western Kenya, 2006.” Epidemiology and Infection, vol. 136, no. 1, pp. 80-91, 2008.

[35] N. A. Sheren, "Knowledge and attitudes of pupils in some primary schools regarding personal hygiene in Erbil city," Kufa Journal for Nursing Sciences, vol. 2, no. 1, pp. 142-150, 2012. 
[36] UNICEF, Clean Hands Save Lives-Global Hand-Washing Day 2011 Is Celebrated by Millions of People Worldwide, UNICEF, New York, NY, USA, Retrieved September 20, 2020.

[37] F. Ruan, T. Yang, H. Ma et al., "Risk factors for hand, foot, and mouth disease and herpangina and the preventive effect of hand-washing," Pediatrics, vol. 127, no. 4, pp. e898-904, 2011.

[38] M. Alzyood, D. Jackson, H. Aveyard, and J. Brooke, "COVID19 reinforces the importance of handwashing," Journal of Clinical Nursing, vol. 29, no. 15-16, pp. 2760-2761, 2020.

[39] X. Chen, L. Ran, Q. Liu, Q. Hu, X. Du, and X. Tan, "Hand hygiene, mask-wearing behaviors and its associated factors during the COVID-19 epidemic: a cross-sectional study among primary school students in Wuhan, China," International Journal of Environmental Research and Public Health, vol. 17, no. 8, p. 2893, 2020 p.

[40] A. S. Bazaid, A. Aldarhami, N. K. Binsaleh, S. Sherwani, and O. W. Althomali, "Knowledge and practice of personal protective measures during the COVID-19 pandemic: a crosssectional study in Saudi Arabia," PloS One, vol. 15, no. 1, p, Article ID e0243695, 2020.

[41] S. P. Luby, M. Agboatwalla, D. R. Feikin et al., "Effect of handwashing on child health: a randomised controlled trial," The Lancet, vol. 366, no. 9481, pp. 225-233, 2005.

[42] S. F. Bloomfield, A. E. Aiello, B. Cookson, C. O’Boyle, and E. L. Larson, "The effectiveness of hand hygiene procedures in reducing the risks of infections in home and community settings including hand-washing and alcohol-based hand sanitizers," American Journal of Infection Control, vol. 35, no. 10, pp. S27-S64, 2007.

[43] F. Alshammary, A. A. Siddiqui, J. Amin et al., "Prevention knowledge and its practice towards COVID-19 among general population of Saudi Arabia: a gender-based perspective," Current Pharmaceutical Design, vol. 27, no. 13, pp. 1642-1648, 2021. 